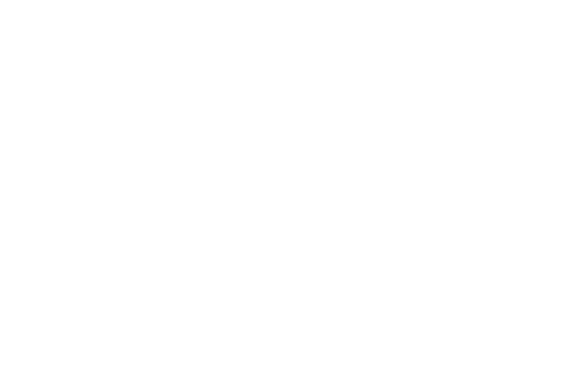

Annu. Rev. Resour. Econ. 2011. 3:313-36

First published online as a Review in Advance on June 10, 2011

The Annual Review of Resource Economics is online at resource.annualreviews.org

This article's doi:

10.1146/annurev.resource.012809.103949

Copyright (C) 2011 by Annual Reviews. All rights reserved

JEL: Q50, Q51, Q58

1941-1340/11/1010-0313\$20.00

\section{Valuing Mortality Risk Reductions: Progress and Challenges}

\author{
Maureen Cropper, ${ }^{1,2}$ James K. Hammitt, ${ }^{3,4}$ and \\ Lisa A. Robinson ${ }^{5}$ \\ ${ }^{1}$ Department of Economics, University of Maryland, College Park, \\ Maryland 20742; email: cropper@econ.umd.edu \\ ${ }^{2}$ Resources for the Future, Washington, DC 20036; email: cropper@rff.org \\ ${ }^{3}$ Department of Health Policy and Management and Center for Risk Analysis, \\ Harvard University School of Public Health, Boston, Massachusetts 02115; \\ email: jkh@harvard.edu \\ ${ }^{4}$ LERNA-INRA, Toulouse School of Economics, 31000 Toulouse, France \\ ${ }^{5}$ Independent consultant; email: lisa.a.robinson@comcast.net
}

\section{Keywords}

value of a statistical life, regulatory analysis, hedonic wage studies, stated-preference studies

\begin{abstract}
The value of mortality risk reduction is an important component of the benefits of environmental policies. In recent years, the number, scope, and quality of valuation studies have increased dramatically. Revealed-preference studies of wage compensation for occupational risks, on which analysts have primarily relied, have benefited from improved data and statistical methods. Stated-preference research has improved methodologically and expanded dramatically. Studies are now available for several health conditions associated with environmental causes, and researchers have explored many issues concerning the validity of the estimates. With the growing numbers of both types of studies, several meta-analyses have become available that provide insight into the results of both methods. Challenges remain, including better understanding of the persistently smaller estimates from statedpreference than from wage-differential studies and of how valuation depends on the individual's age, health status, and characteristics of the illnesses most frequently associated with environmental causes.
\end{abstract}




\section{INTRODUCTION}

The value of mortality risk reductions is a major determinant of the benefits of environmental policies. The quantified benefits of related regulations have long been dominated by the effects of air pollution abatement (U.S. OMB 2010), and the effects of decreased air pollution are in turn dominated by mortality risk reductions. For example, mortality risk reductions account for more than $90 \%$ of quantified benefits of the 1990 Clean Air Act Amendments between 1990 and 2020; the estimated annual benefits total more than $\$ 1.7$ trillion in 2020 (U.S. EPA 2011). Mortality risk reductions also contribute significantly to the benefits of drinking water regulations and many other environmental policies. The types of potentially fatal illnesses associated with these exposures are varied, including heart and lung disease and several types of cancer. Although environmental programs reduce mortality risks to persons of all ages, the largest risk reductions are often enjoyed by older people, who face greater baseline risk: More than $80 \%$ of the life years gained as a result of the Clean Air Act Amendments accrued to individuals age 70 and older (U.S. EPA 2011). Risk reductions accruing to infants and children are generally smaller but are also of concern to decision makers.

Over the past decade, controversies that reflect confusion about basic concepts have erupted over the valuation of these risks (Robinson 2007, Viscusi 2009, Cameron 2010). The value of the small risk reductions associated with environmental policies is often misinterpreted as placing a value on a "life," and information on individuals" willingness to pay (WTP) for their own risk reductions is often misinterpreted as the value that the government places on their lives. These issues have led to calls to clarify related terminology, for example, to reference the value of risk reduction rather than the value per statistical life (VSL). In this article, however, we are concerned with a somewhat different set of issues: the progress and challenges related to conducting empirical research on these values, particularly those that are applicable in the environmental context.

In recent years, the research available to support valuation of environmental risk reductions has evolved significantly. This article discusses important methodological improvements in both revealed- and stated-preference research, summarizes key findings, and notes areas in need of additional work. It explores current standards of methodological acceptance that reflect the evolution of this literature.

Historically, the U.S. Environmental Protection Agency (U.S. EPA) and other agencies have estimated the value of mortality risk reduction primarily using compensating wage differentials: wage premia that workers receive for risks of fatal injuries in the workplace (Robinson 2007, Robinson \& Hammitt 2011). These estimates are based on actual transactions that affect workers' incomes and risks; however, they must be inferred from observational data by holding other job and worker characteristics constant. For valuing environmental risks, compensating wage differentials have two primary drawbacks: They are based on risk of accidental death rather than on environmentally related chronic disease, and the workers whose preferences are assessed are generally less than 65 years of age. Moreover, valuation of occupational and environmental risks may differ if occupational risks are perceived as more voluntary and individually controllable. 
Interest in valuing mortality risks associated with illnesses rather than with injuries, and with nonoccupational exposures, has led to the growing use of stated-preference studies. These studies ask respondents about their WTP for mortality risk reductions of various types and can be tailored to address specific diseases and populations not represented in hedonic wage studies. However, respondents may have less incentive to consider their responses in such studies than in more consequential settings. From the perspective of environmental risk valuation, the important questions are the extent to which statedpreference results are valid and reliable and whether they should replace or supplement hedonic wage estimates.

This article is organized as follows. Section 2 reviews the concept of mortality risk valuation: how much money an individual will substitute for a change in his risk of dying. This is usually expressed as the VSL-that is, the rate of substitution between wealth (or income) and risk. In Section 3, we discuss hedonic wage studies, outlining the methods used and discussing what distinguishes a well-conducted study. We summarize briefly the resulting empirical estimates. Section 4 describes stated-preference studies. We consider the methods used, discuss methodological improvements, and summarize empirical findings. Section 5 concludes by evaluating the empirical literature, proposing criteria for methodologically acceptable studies, and suggesting further research.

\section{THE VALUE PER STATISTICAL LIFE}

Analyses of the health benefits of environmental policies generally begin with a risk assessment that estimates the change in mortality risks likely to be experienced by the affected population. These assessments do not predict which individuals might die if pollution is not abated; they estimate only the change in mortality risk over a defined period for members of the affected population. These changes in mortality risk are often summarized as the expected number of lives saved or premature fatalities averted-that is, the sum over affected individuals of the risk change.

By convention, the value of these risk changes is expressed as the VSL, which is defined as the marginal rate of substitution between money and mortality risk in a defined time period. In other words, it is the local slope of an indifference curve between risk and wealth, not the value of saving an individual's life with certainty (see Hammitt 2000). This means that if an individual is willing to pay $\$ 700$ for a 1 -in-10,000 decrease in his risk of dying during the year, his VSL is $\$ 700$ divided by the risk change, or $\$ 7$ million. The VSL can also be viewed as the sum of what a group of individuals would pay for risk reductions that sum to one statistical life. ${ }^{1}$

The VSL concept is illustrated in Figure 1. Wealth is plotted on the vertical axis, and the probability $(p)$ of surviving a specified period is plotted on the horizontal axis. The curved line represents an individual's indifference curve. For each change in survival probability $(\Delta p)$, individual WTP or willingness to accept (WTA) compensation is measured by the vertical distance between the two points on the indifference curve. The VSL can be calculated as the individual's WTP or WTA divided by $\Delta p .^{2}$

\footnotetext{
${ }^{1}$ Because the term is often misinterpreted (Cameron 2010), U.S. EPA is considering using the term value of risk reduction.

${ }^{2}$ Strictly speaking, VSL is the limit of WTP/ $\Delta p$ and WTA $/ \Delta p$ as $\Delta p$ tends to zero.
} 


$$
\mathrm{VSL} \approx \frac{\mathrm{WTP}}{\Delta p} \approx \frac{\mathrm{WTA}}{\Delta p}
$$

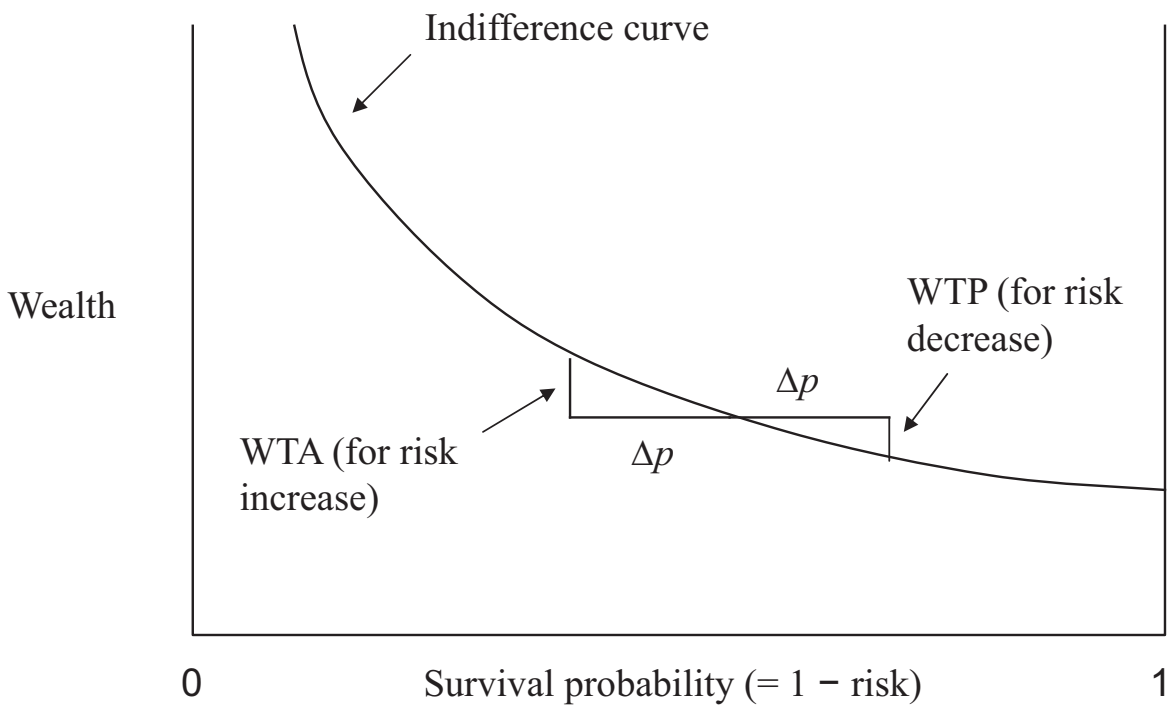

Figure 1

The trade-off between wealth and survival probability.

Intuitively, one expects that individual WTP and WTA will increase with the size of the risk reduction. For small risk changes, the relationship of WTP and WTA to the risk change should be nearly proportional (i.e., the indifference curve is smooth). Proportionality is not expected for large risk changes because wealth constrains the amount one could pay for a large risk reduction (e.g., one could pay $\$ 7$ to reduce risk by 1 in 1 million, but not $\$ 700,000$ to reduce risk by 1 in 10$)$. Under standard assumptions, economic theory suggests that individual WTP will decrease (and WTA will increase) with each incremental increase in the risk reduction (see Hammitt 2000, Hammitt \& Treich 2007).

The relationships illustrated in Figure 1 may be influenced by other factors, including income, wealth, age, life expectancy, current and future mortality risk, and health status. In addition, individuals may place different values on risks with different characteristics. Some of these characteristics are physical attributes (such as whether the risk is latent or involves significant morbidity prior to death); others are psychological (such as whether the risk is perceived as voluntarily incurred or under an individual's control). There is no single VSL: Different people may have different preferences, and for an individual, the value of a 1-in-10,000 risk reduction may depend on whether death results immediately from injury or from a lingering illness, whether it is caused by a hazard viewed as particularly fearsome, whether one is rich or poor or old or young, and other factors. Given these differences, analysts are often faced with challenges related to the match between the available research and the characteristics of the risks and populations of concern in particular environmental contexts. 


\section{HEDONIC WAGE STUDIES}

Historically, the VSL literature has been dominated by revealed-preference studies that estimate the trade-off between wages and job-related risks. ${ }^{3}$ In hedonic wage studies, researchers compare wages of workers in different occupations or industries who face different levels of on-the-job mortality risk, using statistical methods to control for other factors (such as education or nonfatal job risks) that affect wages. Although these studies are often seen as more credible than stated-preference studies, they have two weaknesses: Compensating wage differentials must be inferred statistically, rather than being observed directly, and estimates of VSL based on hedonic wage equations assume that the measure of job risk used by the researcher matches workers' risk perceptions. In addition, hedonic wage estimates are necessarily limited to studying preferences of workers; individuals who are outside the labor market, whether because of illness, retirement, child raising, or other reasons, are not represented. This selection effect may yield a downward bias, as the workers who accept hazardous jobs are likely to be those who demand the least compensation (i.e., have smaller VSLs).

The premise underlying compensating wage differentials is that jobs can be characterized by various attributes, including risk of accidental death. The association between wages and occupational risks observed in the market is determined jointly by workers' preferences and firms' costs of reducing job risks. If workers are well informed about risks of fatal and nonfatal injuries and if labor markets are competitive, riskier jobs should pay more (if worker and other job attributes are held constant). Empirically, wages are described as a function of worker characteristics (age, education, human capital) and job characteristics, including risk of fatal and nonfatal injury (Viscusi 1993). In theory, the difference in wage associated with a small change in risk equals the amount of compensation a worker requires to accept the risk and the income he would forego for a safer job.

A few hedonic wage studies have used workers' perceived risks (elicited by survey) in place of conventional actuarial risk estimates (e.g., Gerking et al. 1988, Gegax et al. 1991, Viscusi \& Moore 1991, Liu \& Hammitt 1999). These studies yield VSL estimates similar to those of studies using actuarial risk estimates, as confirmed by meta-analysis (Mrozek \& Taylor 2002).

A typical hedonic wage equation is of the form in Equation 1, in which the log of the wage is regressed on fatal and nonfatal job risk, worker characteristics (including age, race, education, years of experience, and union status), and job characteristics (including industry and occupation). ${ }^{4}$

$$
\text { In } w_{i}=\alpha+\sum \beta_{m} x_{i m}+\gamma_{0} r_{i}+\gamma_{1} q_{i}+\gamma_{2} q_{i} W C_{i}+u_{i},
$$

where $w_{i}$ is worker $i$ 's wage rate, $\alpha$ is a constant, $x_{i m}$ are personal and job characteristics for worker $i, r_{i}$ is the fatal job risk for worker $i, q_{i}$ is the nonfatal job risk for worker $i$,

\footnotetext{
${ }^{3}$ Studies of risk-averting behavior (or demand for consumer-safety products) and residential-property values have also been used to estimate VSL (see reviews by Viscusi \& Aldy 2003 and Blomquist 2004). Researchers often argue that these studies are less suitable for valuation than are hedonic wage or stated-preference studies because of difficulties in estimating actual or perceived risks, the need to make assumptions about key factors such as time costs (in some product studies), whether cancers are likely to be fatal (in some hedonic property value studies), and other factors.

${ }^{4}$ The extent to which industry and occupation dummy variables can be included is limited by the nature of the risk data. If fatal job risk is estimated at the three-digit industry level, then two-digit industry dummy variables, but not three-digit dummies, can be included in the equation to avoid exact collinearity among right-hand variables.
} 
$W C_{i}$ is worker $i$ 's compensation, and $u_{i}$ is a random error term. Because $\gamma_{0}$ represents the proportionate increase in the wage for a one-unit change in fatal job risk, VSL is calculated by multiplying $\gamma_{0}$ by the average wage and dividing by a one-unit change in risk. ${ }^{5}$

\subsection{Econometric Issues}

The econometric difficulties encountered in estimating the labor market price of risk include obtaining accurate estimates of risk of death on the job; the sensitivity of estimates of $\gamma$ to what other variables are included in the equation-in particular, sensitivity to the inclusion of industry and occupation dummies and a measure of nonfatal job risk; and correlation between job risk and variables omitted from the equation. The last problem can take several forms. If higher-risk jobs have undesirable characteristics not measured by the researcher, the risk variable will tend to capture these characteristics, biasing $\gamma_{0}$ upward. Unmeasured worker characteristics could bias the coefficient of risk in either direction. If worker productivity is measured imperfectly and more productive workers accept safer jobs, this will bias $\gamma_{0}$ downward (Hwang et al. 1992). Unmeasured differences in workers' ability to reduce job risk will tend to bias $\gamma_{0}$ upward (Shogren $\&$ Stamland 2002).

The magnitude of the econometric difficulties associated with early wage-risk studies is documented by Black et al. (2003) and by Black \& Kniesner (2003). At the request of U.S. EPA, Black et al. estimated hedonic wage equations using 10 combinations of worker and risk data sets that are commonly used in hedonic wage studies. ${ }^{6}$ Four specifications of Equation 1 were estimated for each data set: $(a)$ a basic set of covariates (model 1), ${ }^{7}$ (b) the basic set with state dummies (model 2), (c) model 2 with occupation or industry dummies (model 3 ), and $(d)$ model 2 with both occupation and industry dummies. The authors find that the estimated coefficient on fatal risk varies widely; it is positive and significantly different from zero in only 16 (of 40) cases for men and in 14 (of 40) cases for women. They attribute the instability of estimated VSLs to errors in measuring fatal job risk, which may be correlated with worker attributes, and to collinearity between the risk measure and occupation and industry dummies. The authors conclude, "Collectively, these findings lead us to have severe doubts about the usefulness of existing estimates to guide public policy."

Over the past 10 years, the data and methods used in U.S. hedonic wage studies have improved significantly. We discuss the availability of improved risk data, attempts to control for confounding factors, and methods for dealing with the endogeneity of job risk. We document progress in dealing with these econometric challenges and areas that remain open for future research. Section 3.2 provides examples of recent studies and metaanalyses.

\footnotetext{
${ }^{5}$ The change in wage and risk must be calculated for the same time period, usually annual.

${ }^{6}$ The data sets are obtained by combining either the March Current Population Survey, the Outgoing Rotation Groups of the Current Population Survey, or the National Longitudinal Survey of Youths with risks by industry or by occupation from either the Bureau of Labor Statistics Survey of Working Conditions or the National Institute of Occupational Safety and Health estimates from its National Traumatic Occupational Fatality survey.

${ }^{7}$ The basic set of covariates differs between data sets but includes a quartic function of age, education, union and marital status, race, and ethnicity. Some data sets also include firm size, workers' experience, tenure, and/or score on the Armed Forces Qualification Test.
} 
3.1.1. Measurement of job risk. Accurate measurement of fatal job risk requires estimates that vary by both occupation and industry and that, because of the infrequency of deaths on the job, are based on a large sample of workers. Random errors in measuring fatal job risks tend to bias estimated coefficients toward zero, understating compensating wage differentials. Most studies prior to 2000 used data from either the Bureau of Labor Statistics (BLS) Survey of Occupational Injuries, reporting deaths by three-digit industry classification, or the National Institute of Occupational Safety and Health (NIOSH), reporting risks by one-digit industry and state, resulting in significant measurement problems. ${ }^{8}$ Clearly, workers in different occupations within the same industry are subject to different risks: An office worker in a mining company faces less risk than a miner. There is also evidence that the early BLS data understated fatal job risks.

Recent studies (Viscusi 2004, Aldy \& Viscusi 2008, Kniesner et al. 2010) have made significant advances in the measurement of job risk by using the BLS Census of Fatal Occupational Injuries (CFOI) and distinguishing risks by occupation and industry. ${ }^{9}$ The CFOI is a census rather than a sample and is based on a comprehensive review of multiple records, including death certificates and workers' compensation reports. These studies generally use risks for 720 occupation-industry cells (10 occupations and 72 two-digit industries) based on three-year averages of deaths.

3.1.2. Sensitivity to equation specification and omitted variables. The sensitivity of estimates of the labor market price of risk to equation specification has been noted by many authors, including Leigh (1995), Mrozek \& Taylor (2002), Black et al. (2003), and Hintermann et al. (2010). Failure to control for either worker or job characteristics that are correlated with job risk will make estimates of the coefficient $\gamma_{0}$ biased and inconsistent. Estimates are especially sensitive to the inclusion of dummy variables for occupation and industry and to the inclusion of nonfatal job risk and replacement of wages through workers' compensation programs (e.g., Viscusi 2004). Occupation dummies are often included in Equation 1 to proxy job characteristics, which, apart from injury risk, are seldom included in compensating wage studies. ${ }^{10}$ Interindustry wage differentials may occur for reasons unrelated to job risk-for example, because of differences in capitallabor ratios (Krueger \& Summers 1988)—suggesting that industry dummies should be included in hedonic wage equations.

Correlations between $(a)$ fatal job risk and $(b)$ industry or occupation make estimates of the price of risk sensitive to their inclusion. Leigh (1995) and Dorman \& Hagstrom (1998) argue that the estimated price of risk actually captures interindustry wage differentials because the coefficient on risk often becomes insignificant when industry dummies are included. In their meta-analysis, Mrozek \& Taylor (2002) find that studies that include industry dummies obtain significantly lower estimates of the price of risk compared with

\footnotetext{
${ }^{8}$ Some studies from the 1970 s and 1980 s (e.g., Thaler \& Rosen 1976, Brown 1980) used data from the Society of Actuaries, which measured total death rate by occupation, including nonoccupational deaths (that would not attract a wage premium). Dillingham (1985) is a notable exception of an early study that measured risks by occupation and industry.

${ }^{9}$ Available at http://www.bls.gov/iif/home.htm.

${ }^{10}$ Some studies distinguish or include only blue-collar jobs or include measures of physical exertion and other working conditions. Deliere et al. (2009) use detailed occupation characteristics from the Dictionary of Occupational Titles to characterize jobs.
} 
studies that exclude them. Viscusi (2004) finds that controlling for both industry and occupation risk reduces the estimated VSL by half compared with controlling only for industry.

Correlation between industry or occupation and fatal job risk is a problem of collinearity. A similar problem arises when risk of nonfatal injury is included in the hedonic wage equation. Nonfatal job risk is generally correlated with fatal job risk, making it difficult to disentangle the effects of the two variables. A possible solution is to find data sets that exhibit less collinearity between these variables.

3.1.3. Endogeneity of risk. The level of occupational fatality risk a worker faces results not from random assignment of workers to jobs but from a sorting process in which workers choose among jobs for which they are qualified. Moreover, workers may differ in their ability to manage occupational risks so that even workers in the same job face different risks (Shogren \& Stamland 2002).

Correlation between risk and unobserved job or worker characteristics can be handled using instrumental variables or panel data. Finding a good instrumental variable for job risk has proved difficult. Arabsheibani \& Marin $(2000,2001)$ attempt to treat risk as endogenous but find that collinearity between their instrument and other covariates makes precise estimation difficult. Kniesner et al. (2010) and Hintermann et al. (2010) use past risk levels as instruments for the change in worker risk in their studies. ${ }^{11}$ Another possibility is to find a natural experiment, such as that resulting from a government program to reduce traffic fatalities, that causes variation in fatal job risk and is exogenous to both unmeasured job and worker characteristics.

When panel data are available, estimation of Equation 1 using first differences or worker fixed effects will eliminate worker characteristics that change slowly over time from the error term. ${ }^{12}$ Kniesner et al. (2011) and Hintermann et al. (2010) use panel data sets to estimate compensating wage differentials for the United States and the United Kingdom, respectively. Kniesner et al. note that most of the variation in risks over time comes from job changes rather than from changes in risk, holding job constant. There is sufficient within-worker variation in risk in the Panel Study of Income Dynamics to obtain precise estimates of VSL. ${ }^{13}$ The authors also note that controlling for unobserved worker heterogeneity reduces VSL estimates by approximately $50 \%$ from estimates obtained using a single cross section of data. In contrast, Hintermann et al. do not find statistically significant estimates of VSL when using panel data, although they do find significant results when estimating Equation 1 by ordinary least squares.

The econometric issues discussed here suggest that one must be careful in interpreting published studies-especially those conducted prior to 2000-as providing unbiased estimates of the price of risk in the labor market. Although more sophisticated econometric methods are now being used, estimates currently applied in policy analysis are based

\footnotetext{
${ }^{11}$ The use of first differences in risk helps to attenuate measurement error in the risk variables, as does the use of instrumental variables for risk. Black \& Kniesner (2003) note that instruments are useful in addressing classical measurement error but that improved methods are needed to address the nonclassical error found in the older hedonic wage studies.

${ }^{12}$ These characteristics may include risk preferences, unmeasured job productivity, and unmeasured safety-related productivity. An alternate approach to dealing with unmeasured worker productivity is to estimate a Roy sorting model (see Deliere et al. 2009).

${ }^{13}$ These estimates are obtained by omitting industry dummies.
} 
Table 1 U.S. estimates from recent hedonic wage meta-analyses ${ }^{a}$

\begin{tabular}{l|l|l|l}
\hline \multirow{2}{*}{\multicolumn{1}{c|}{ Meta-analysis }} & \multirow{2}{*}{$\begin{array}{c}\text { Publication dates of } \\
\text { underlying studies }\end{array}$} & \multicolumn{1}{c}{ Highlighted VSL estimate } \\
\cline { 3 - 4 } & $1974-1990$ & As reported (dollar year) & \multicolumn{1}{c}{${\text { Inflated to 2009 } \text { USD }^{\mathrm{d}}}^{\mathbf{c}}$} \\
\hline Miller (2000) & \$3.7 million (1995 USD) & \$5.2 million \\
\hline Mrozek \& Taylor (2002) & $1974-1995$ & $\$ 1.5$ million to \$2.5 million (1998 USD) & \$2.0 million to \$3.3 million \\
\hline Viscusi \& Aldy (2003) & $1974-2000$ & $\$ 5.5$ million to \$7.6 million (2000 USD) & \$6.9 million to \$9.5 million \\
\hline Kochi et al. (2006) & $1974-2002$ & $\$ 8.9$ million (2000 USD) & \$11.1 million \\
\hline
\end{tabular}

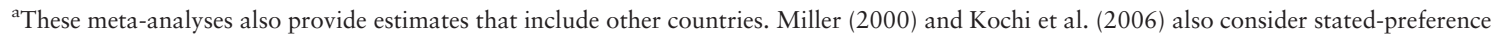
studies.

${ }^{\mathrm{b}} \mathrm{U} . S$. hedonic wage studies only.

${ }^{\mathrm{c}}$ Mean or median estimate(s) for the United States, highlighted by the authors in their abstracts or in discussions of alternative models.

dAdjusted for inflation using the Consumer Price Index, All Urban Consumers. Not adjusted for income growth over time.

primarily on earlier literature. With this caveat, we briefly summarize the findings of the empirical literature.

\subsection{Empirical Estimates of the Price of Risk in the Labor Market}

According to Viscusi \& Aldy (2003), more than 60 hedonic wage studies have been conducted worldwide. Several meta-analyses summarize the VSL estimates and explore the factors that underlie the variation. In addition, some studies investigate issues relevant to the use of hedonic wage research to value environmental risks, including the age of those affected and the extent to which mortality risks are associated with illnesses rather than with injuries.

3.2.1. Meta-analyses of hedonic wage studies. The hedonic wage literature includes several dozen studies that have been summarized in a series of meta-analyses; the four metaanalyses listed in Table 1 provide U.S. estimates. ${ }^{14}$ Each of these meta-analyses constructs a best estimate of VSL. The first three use meta-regression to see how VSL estimates from individual studies vary with study and respondent characteristics. The fourth, Kochi et al. (2006), uses a Bayesian approach to adjust estimates for within- and between-study variability. Although all four meta-analyses include VSL studies of non-U.S. populations (almost entirely populations in high-income countries), we focus on the authors' preferred estimates for the United States. Approximately 30 to 40 U.S. hedonic wage studies are included in each meta-analysis (the exact number varies across model specifications). The resulting U.S. estimates range from $\$ 2.0$ million to \$11.1 million (2009 USD). ${ }^{15}$

The best estimates obtained by each meta-analysis vary because each includes a somewhat different set of studies and estimates, investigates different modeling approaches

\footnotetext{
${ }^{14}$ Several other meta-analyses focus on estimating VSL for countries other than the United States. Liu et al. (1997) and Bowland \& Beghin (2001) include only hedonic wage estimates. Kluve \& Schaffner (2008) and de Blaeij et al. (2003) include both revealed- and stated-preference studies; the latter is a meta-analysis of road safety studies.

${ }^{15} \mathrm{~A}$ more recent meta-analysis of both revealed- and stated-preference studies from around the world, Bellavance et al. (2009), includes U.S. hedonic wage studies published between 1974 and 2004 along with other studies and uses a mixed-effect regression model. The weighted average of Bellavance et al.'s estimated VSLs is $\$ 5.9$ million (with a $95 \%$ confidence interval of $\$ 4.7$ million to $\$ 7.1$ million) in 2000 USD or $\$ 7.3$ million in 2009 USD.
} 
and model specifications, and explores the inclusion of different covariates. The metaregressions conducted by Miller (2000), Mrozek \& Taylor (2002), and Viscusi \& Aldy (2003) explain variation in VSL estimates across studies as a function of study and population characteristics. These include variables such as mean worker income, mean occupational risk, the proportion of workers unionized, and whether the study included controls for interindustry wage differentials or nonfatal job risk. All the meta-analyses find that VSL increases with the average income of workers in the study, although the rate of increase varies. Mrozek \& Taylor (2002) find that studies that fail to control for interindustry wage differentials report larger VSLs.

Unfortunately, almost all the hedonic wage studies included in these meta-analyses were completed before the improved CFOI data became available, and these older studies also do not reflect recent advances in econometric modeling. There is no published metaanalysis that covers the newer hedonic wage literature; the most current (Bellavance et al. 2009) includes studies published only through 2004, whereas the first study to use the CFOI data was Viscusi (2003). ${ }^{16}$

3.2.2. Effects of worker age and risk characteristics. Most hedonic wage studies estimate an average price of risk in the job market and do not measure how compensating wage differentials vary by risk or worker characteristics. ${ }^{17}$ Some studies have examined how the price of risk varies with worker age and cause of death. ${ }^{18}$ We summarize examples of recent results here, focusing on attributes that are most relevant to valuing environmental risks.

3.2.2.1. Age. Aldy \& Viscusi (2008) examine the effect of age on VSL using CFOI risk data that vary by worker age and industry and a minimum-distance estimator that controls for cohort effects (younger workers were born later and have greater lifetime income). They find that VSL follows an inverted-U pattern with age, peaking at approximately $\$ 8$ million (2000 USD) at age 46 and then declining to $\$ 5$ million by age 62 . Other hedonic wage studies also find this inverted-U relationship (Aldy \& Viscusi 2007). In contrast, a series of studies by Evans, Smith, and colleagues find somewhat differing results, focusing on workers aged 51 to 65 and using panel data from the Health and Retirement Survey. Smith et al. (2004) find that estimated VSL increases with age, Evans \& Smith (2006) find that quality of life and background risks complicate this relationship, and Evans \& Smith (2008) note that health may confound estimated age effects. In the latter study, for its sample of workers, it finds that VSL is larger for workers with better current health and for those who face larger near-term risk. ${ }^{19}$

\footnotetext{
${ }^{16}$ U.S. EPA (2010b) identifies 15 studies that use the CFOI data, of which 8 use the data in original hedonic wage analyses.

${ }^{17}$ VSL increases with income, although the rate of increase is uncertain. See Hammitt \& Robinson (2011) for a review.

${ }^{18} \mathrm{~A}$ few studies estimate how compensation varies with other worker characteristics. For example, Viscusi \& Hersch (2001) find that smokers receive smaller compensation for nonfatal injury risk than do nonsmokers, and Viscusi (2003) finds that blacks receive less compensation for risk than do whites.

${ }^{19}$ Smith et al. (2004) and Evans \& Smith (2006) use BLS industry-level risk, but Evans \& Smith (2008) use CFOI data that vary by industry and worker age. 
3.2.2.2. Risk characteristics. Nearly all hedonic wage studies estimate compensation for risk of fatal injury and exclude risks of fatal disease (which are much more uncertain). An exception is Lott \& Manning (2000), who estimate compensation for risk of fatal cancer. The authors use several indicators of worker exposure to carcinogens at the two-digit standard industry classification level in place of a standard fatality risk measure and estimate the corresponding wage premium. They provide "rough" estimates of VSL, using a range of assumptions about the fatality risk of occupational exposure, that range from $\$ 1.2$ million to \$12 million in 1984 U.S. dollars or from \$2.5 million to \$24.8 million in 2009 U.S. dollars.

Recent work by Scotton \& Taylor (2011) suggests that hedonic wage estimates may mask significant heterogeneity in the value of different types of risks. Using risk rates that vary by cause of injury, they find that wage premia are much higher for workplace homicides than for other job-related risks. Although their results are not directly applicable to illness-related risks from environmental causes, they suggest that more work is needed to understand how different fatality risks are valued.

\section{STATED-PREFERENCE STUDIES}

Stated-preference studies, which survey respondents about how they would act in hypothetical situations, have become increasingly common as a means of valuing mortality risk reductions. The scenario presented to respondents can be tailored to specific environmental risks (e.g., pesticide residues or air pollution) and causes of death (e.g., cancer or heart disease). It can provide detailed information about latency and the time path of any illness preceding death (Cameron et al. 2010). Risks may affect persons of all ages, including children and the elderly, and the researcher is at liberty to specify the size of the risk reduction. The disadvantage of stated-preference studies is that individuals may give spurious answers because they face no real consequences. An indication of problematic responses is that estimated WTP often fails to increase in proportion to the size of the risk reduction valued, and thus estimates of VSL decrease sharply as the stated risk reduction increases. Furthermore, estimates from stated-preference studies are sensitive to assumptions made in the econometric analysis.

Most stated-preference studies are either contingent valuation (CV) studies or choice experiments. In both cases, the respondent is presented with a scenario (often a product or a program) that would reduce his mortality risk and with information about his baseline risk (without the program). The researcher must define the magnitude of the risk reduction delivered by the program, the time period over which it will be delivered, the amount and form of payment (e.g., product price increase or additional taxes), and other relevant information. The respondent is asked to make a choice: in the case of CV, whether he would choose the program and pay the stated cost, or in a choice experiment, which of several programs he would choose. ${ }^{20}$ Studies usually include multiple valuation questions plus debriefing questions to determine whether the respondent understood and accepted the choices offered.

\footnotetext{
${ }^{20}$ For example, Cameron \& DeShazo (2008) present respondents with scenarios that represent different lifetime illness profiles, including 12 types of health risks (cancers, cardiovascular and respiratory diseases, other illnesses, and traffic accidents) that vary in the timing of the risk reduction and its magnitude.
} 


\subsection{Choices in Study Design}

Researchers must make many decisions in determining how to design stated-preference studies, including how to define the risk to be valued, how to clearly communicate the magnitude of the risk, and how to best elicit WTP. Each of these choices can affect both the validity of the resulting estimates and their applicability to valuing risk reductions associated with control of environmental hazards.

4.1.1. Nature of the risk valued. An important issue in survey design is whether respondents should value reductions in risk of death due to a specific cause (e.g., heart disease or cancer) without indicating whether the risk of death is linked to the environment or whether the risk of death should be identified as resulting from an environmental problem, such as air pollution or hazardous waste sites. The danger with the latter approach is that respondents may not accept the scenario: They may not believe that the environmental problem could result in the stated health effect, they may be unwilling to pay to reduce the risk because they did not cause it, they may not believe that the described program would be effective, or their values may reflect a desire to modify some other feature of the problem. ${ }^{21} \mathrm{~A}$ danger associated with instead asking about a more abstract risk reduction that is not linked to a specific hazard and program for amelioration is that the respondents may not find the scenario credible and may reject it out of hand. Because environmental programs often benefit the community at large rather than solely the individual respondent, it is important to understand whether the respondents are valuing only their own risk reduction or the reductions provided to the larger community.

A recent Organization for Economic Cooperation and Development (OECD) review of the international stated-preference literature (Lindhjem et al. 2010) identified 75 VSL surveys, of which 18 focused on environmental causes, 28 on health risks from unspecified causes, and 29 on traffic safety. Examples of environmental and health-related studies include those focused on the risk of cancer from pesticide residues (Hammitt \& Haninger 2010), the risk of death from exposure to hazardous waste (Alberini et al. 2007), and the risk of death due to chronic heart and lung disease (Krupnick et al. 2002).

4.1.2. How risks are communicated. A critical component of any mortality risk survey is how baseline risks and risk changes are communicated. Baseline risk is the respondent's risk of dying without the program or product, usually from all causes. The risk changes are typically on the order of 1 in 10,000 or 1 in 100,000 per year. Lay people have difficulty comprehending small probabilities, which may lead them to report values that are not logically related to the size of the risk reduction (Hammitt \& Graham 1999). ${ }^{22}$

Methods for communicating risk changes depend on survey mode. For in-person, mail, and Internet surveys, risks are often communicated by coloring squares on a grid, a method that yields responses to valuation questions that are more consistent with theory (Corso et al. 2001). Other devices used to communicate small probabilities include risk ladders, which compare the risk in question with other risks using a linear or logarithmic scale. In telephone surveys, individuals are sometimes told that without a program " $x$ people will

\footnotetext{
${ }^{21}$ In a study of pesticide residues on foods, Hammitt \& Haninger (2010) found that $32 \%$ of respondents thought their personal risk was overstated in the survey and that $12 \%$ thought it was understated.

${ }^{22}$ Hammitt \& Graham (1999) found that 39\% of telephone-survey respondents did not correctly answer which is the larger number: 1 in 10,000 or 5 in 100,000.
} 
die out of 10,000 " and that with the program " $y$ people will die out of 10,000." A disadvantage of this approach is that it focuses attention on the change in risk to a population rather than on the change in risk to the individual respondent (who may perceive that he will not benefit). Lindhjem et al. (2010) describe trends in survey mode, reporting that the use of Internet and computer-based surveys is increasing rapidly and that most surveys now use some sort of visual aid.

4.1.3. Elicitation of willingness to pay. How respondents are asked to value a risk reduction affects the quality of the data obtained and how responses are analyzed. Before the mid-1990s, most mortality risk valuation surveys used open-ended valuation questions. Respondents were asked, "What is the most you would pay for the risk change?" This has the advantage of providing a point estimate of each person's WTP but is a difficult question to answer and may elicit a strategic response (e.g., because people are conditioned not to report their maximum WTP in negotiations).

In the majority of CV studies conducted since the mid-1990s, dichotomous-choice methods are used, following the recommendation of the U.S. National Oceanic and Atmospheric Administration (NOAA) expert panel on CV (NOAA 1993). Respondents are asked a neutral question about whether they would pay a stated amount for the risk reduction ("If the risk reduction cost $\$ z$, would you purchase it or not?"), and the so-called bid amount $z$ is varied randomly across respondents. The question is often followed by a second question to more closely bound the respondent's WTP. For example, if the respondent accepts the program when the bid is $\$ 100$, he is asked whether he would accept or reject it if the bid were $\$ 200$. If he rejects $\$ 200$, his WTP is assumed to be between $\$ 100$ and $\$ 200$; if he accepts $\$ 200$, it is assumed to be greater than $\$ 200$ with no explicit upper bound..$^{23}$ Although dichotomous-choice questions do not invite strategic response, they provide only interval estimates of each respondent's WTP. The precision of the final estimate is sensitive to the bids chosen. ${ }^{24}$

For benefit-cost analysis, analysts usually seek to measure mean WTP because population benefits can be calculated as the product of mean WTP and the number of people affected. Mean WTP for a risk change can be calculated easily from open-ended responses but may be sensitive to outliers, some of which may be invalid "protest" responses, in which the respondent reports zero or a very large number as a way of rejecting the premise of the question. In the case of a single dichotomous-choice question, the proportion of people willing to pay $\$ z$ provides a point estimate of the cumulative distribution of WTP. Plotting raw responses against bid amounts provides an estimate of the distribution of sample WTP. A lower-bound estimate of mean WTP may be obtained from these responses using a Turnbull estimator, which assumes that each individual's WTP is equal to the largest bid he accepts (Turnbull 1974).

In practice, mean WTP is estimated from dichotomous-choice data by assuming that WTP is a function of covariates (i.e., $\mathrm{WTP}_{i}=X_{i} \beta+\varepsilon_{i}$, where $\varepsilon_{i}$ is an error term) and then estimating the parameter vector $\beta$, making assumptions about the distribution of $\left\{\varepsilon_{i}\right\}$.

\footnotetext{
${ }^{23}$ Payment cards that list alternative WTP amounts are sometimes used. Respondents are asked to circle the amount that most closely matches their WTP or to circle the two numbers that bracket their WTP. A disadvantage is that responses are sensitive to the range of values displayed on the card (a result that is well known to charities that suggest specific donations).

${ }^{24}$ See Alberini (1995) for more discussion of optimal bid design.
} 
For example, in the case of a single dichotomous-choice question, if $\left\{\varepsilon_{i}\right\}$ are independently and identically normally distributed with zero mean and standard deviation $\sigma$, the probability that the respondent will not pay more than $z_{i}$ is $\Phi\left(z_{i} / \sigma-X_{i} \beta / \sigma\right)$, where $\Phi$ is the standard normal distribution function. By estimating a probit model with $z$ and $X$ as independent variables (Cameron \& James 1987), one obtains estimates of $1 / \sigma$ and $\beta / \sigma$. Mean WTP (conditional on $X$ ) is computed as $X \beta .^{25}$ This approach also makes it possible to estimate the relationship between covariates (such as age and income) and WTP. Because WTP is usually assumed to be nonnegative and the distribution is often skewed, with a long right tail, asymmetric distributions like the lognormal and Weibull are frequently used. With these distributions, the mean is sensitive to the weight of the right tail, which is not well estimated (because few respondents are in the tail, yet hypothetical bias may induce some respondents to overstate their WTP, yielding too heavy a tail). As a result, median WTP is often reported, even though the mean is more relevant for benefit-cost analysis.

\subsection{Issues Regarding Responses and Data Analysis}

Regardless of how these survey design issues are resolved, researchers also face challenges related to interpreting and analyzing the responses. Some of these challenges relate to the hypothetical nature of the scenario assessed, and others relate to the limited information about the shape of the distribution that underlies the individual responses.

4.2.1. Hypothetical nature of responses. A major concern with stated-preference studies is that respondents may give different answers than they would if they faced real consequences. They may not take questions seriously (i.e., they may not give thoughtful responses), or they may say "yes" to payment questions to please the interviewer (yeasaying) or say "no" to protest the scenario offered (nay-saying). If respondents do not have to pay, they may not seriously consider their budget constraints.

One method of addressing these concerns is to compare actual with stated WTP for identical risk changes. A large literature compares actual with stated WTP for other commodities. For example, several experiments comparing hypothetical and actual WTP for hunting permits find no statistically significant difference (Dickie et al. 1987, Mitchell \& Carson 1989). Few such studies address mortality risks. Lanoie et al. (1995) conducted a CV survey in Montreal and collected the information needed to develop hedonic wage estimates. They find that the two approaches yielded different results but suggest that their sample may be too limited to permit general conclusions. Hakes \& Viscusi (2007) compare the VSL implied by seatbelt use data with the VSL from a stated-preference study and find no statistically significant difference.

Tests of internal validity, which are now a standard part of most CV studies, are another way of addressing concerns about the hypothetical nature of stated-preference surveys, as are debriefing questions asked at the end of the survey. ${ }^{26}$ Internal validity can be evaluated by testing whether estimated WTP is sensitive to factors that should affect it (such as the magnitude of the risk change that is valued and the respondent's income) and is insensitive to factors that should not affect it (such as small differences in baseline risk). WTP should

\footnotetext{
${ }^{25}$ Maximum likelihood techniques can likewise be used to estimate the parameter vector $\beta$ in the case of doublebounded dichotomous-choice questions, given assumptions about the distribution of the error term.

${ }^{26} \mathrm{It}$ is possible to test for yea- and nay-saying (Alberini 2005), although this is rarely done.
} 
increase with income. Indeed, the income elasticity of WTP should exceed the coefficient of relative risk aversion (Eeckhoudt \& Hammitt 2001, Kaplow 2005). In most statedpreference studies, WTP increases with income, but the income elasticity is less than one (Hammitt \& Robinson 2011).

It is standard practice to debrief respondents at the end of a survey to see whether they interpreted the questions as the researcher intended. For example, respondents in a mortality risk survey may consider the morbidity that precedes death as well as mortality per se, even if no mention was made of morbidity. Or they may believe that the risks associated with an environmental contaminant are higher or lower than stated in the survey. Respondents are often asked how confident they are in their responses. This information can be used to adjust WTP either by removing some respondents from the sample or by statistically controlling for respondent reactions.

4.2.2. Failure of willingness to pay to increase with the size of the risk reduction. Mortality risk survey designers often include scope tests to determine whether WTP to reduce risk increases with the magnitude of the risk reduction. External scope tests compare WTP between subsamples of respondents presented with different risk changes. These tests are preferred to internal scope tests that compare WTP by the same respondents, as internal tests can be influenced by respondents' efforts to provide self-consistent responses. As described in Section 2, WTP should increase approximately in proportion to the size of the risk reduction, implying that VSL remains constant. External scope tests are usually interpreted as testing both whether risk changes are interpreted by respondents in an objective fashion and whether responses accord with theory. ${ }^{27}$

Although many studies find that WTP increases with the size of the risk reduction, WTP often fails to increase proportionately. Hammitt \& Graham (1999) identify 25 studies that estimated WTP for numerically specified health risk reductions published between 1980 and 1998. Of the nine studies that include external scope tests, WTP is significantly associated with risk change in six but is never proportional to risk change. In a more recent review of studies that examined the effect of age on VSL, Krupnick (2007) reports that 20 of the 28 studies that conducted scope tests show sensitivity to the size of the risk change, but he does not discuss the extent to which the changes are proportional. Corso et al. (2001) tested the sensitivity of WTP to risk change using several visual aids and external scope tests. They find that WTP is proportional to the risk change using one visual aid and is nearly so using another. However, even in studies using these techniques, WTP often fails to increase in proportion to the size of the risk reduction. For example, Alberini et al. (2004) find that mean WTP of U.S. respondents for a reduction in risk of death of 5 in 1,000 over 10 years was approximately 1.6 times the WTP for a risk reduction of 1 in 1,000 .

We believe that it is important for stated-preference studies to test for sensitivity to the size of the risk reduction, both within and between groups of respondents. Passing at least a weak form of the external scope test, in which WTP increases with risk reduction, should be a criterion for an acceptable study. In a recent data set of stated-preference studies compiled by U.S. EPA (2010b), only approximately half the estimates were subject to a

\footnotetext{
${ }^{27}$ Similar tests are not conducted in hedonic wage studies. To identify how respondents' preferences vary with the size of the risk change would require estimating workers' bid functions (as in Biddle \& Zarkin 1988) but without imposing assumptions that restrict their shape.
} 
scope test; of these, $90 \%$ of the VSL estimates passed a weak external scope test, but only $15 \%$ passed a strong form of the test (which requires that WTP be nearly proportional to the risk reduction).

4.2.3. Sensitivity of results to econometric analysis. Although it is always possible to report the distribution of WTP responses from the raw data, most articles report WTP estimates after applying distributional assumptions to address data gaps. The nature of these assumptions can have profound effects on estimates of mean WTP and on estimates of the association of covariates with WTP (Alberini 2005). When WTP is assumed to have a normal or logistic distribution, predicted WTP may be negative for a significant fraction of the sample and can result in a mean WTP that is negative. This is sometimes handled by computing WTP on the basis of the positive portion of the WTP distribution (Johannesson et al. 1997) but more often by assuming that WTP has a lognormal or Weibull distribution. Alberini (2005) illustrates the effect of alternative distributional assumptions on estimates of mean WTP. For example, mean WTP based on data from Johannesson et al. (1997) ranges from -2,100 Swedish krona (SEK) using a normal distribution to 2.9 million SEK using a Weibull distribution. The sensitivity of WTP to distributional assumptions should be tested in all studies.

\subsection{Empirical Estimates of VSL from Stated-Preference Studies}

Over the past 10 years, the number of stated-preference studies estimating VSL has increased significantly. The 26 VSL estimates that the U.S. EPA used in its analyses for many years (U.S. EPA 2010a) include only 5 from stated-preference studies on the basis of reviews published almost 20 years ago (Viscusi 1992, 1993). In contrast, the recent OECD review (Lindhjem et al. 2010) identified 68 stated-preference VSL studies (incorporating 75 surveys) that have been conducted since 1970. More than half of these studies were completed in 2000 or later.

4.3.1. Meta-analysis of stated-preference studies. With the increase in stated-preference research, new meta-analyses that separately consider these studies are emerging. In Table 2, we summarize the meta-analyses that include only stated-preference studies or that provide results separately for stated- and revealed-preference studies. As noted above, Kochi et al. (2006) use a Bayesian approach, as do Dekker et al. (2011); the Lindhjem et al. (2010) OECD study is based on meta-regression. These meta-analyses do not provide estimates solely for the United States, although most of the studies included were conducted in high-income countries. Each meta-analysis combines studies that address environmental, health, and traffic risks; although traffic risks dominate the older studies, an increasing number of studies now address other causes of death. ${ }^{28}$ The resulting VSL estimates range from approximately $\$ 2$ million to $\$ 8$ million (2009 USD).

In contrast to studies valuing environmental quality, stated-preference studies of the value of mortality risk reduction tend to yield smaller estimates than do revealedpreference studies. For example, in the Kochi et al. (2006) meta-analysis, the authors use Bayesian methods to compare the distributions of estimates from hedonic wage and

\footnotetext{
${ }^{28}$ We exclude the de Blaeij et al. (2003) meta-analysis from this discussion because it focuses exclusively on traffic safety. 
Table 2 Stated-preference meta-analyses

\begin{tabular}{|c|c|c|c|}
\hline \multirow[b]{2}{*}{ Meta-analysis } & \multirow{2}{*}{$\begin{array}{l}\text { Publication dates of } \\
\text { underlying studies } \\
\text { (number of studies) }^{\mathrm{a}}\end{array}$} & \multicolumn{2}{|c|}{ Highlighted VSL estimates } \\
\hline & & As reported (dollar year) ${ }^{b}$ & Inflated to 2009 USD $^{c}$ \\
\hline Kochi et al. (2006) & 1988-2002 (14) & $\$ 2.8$ million $(2000)$ & $\$ 3.5$ million \\
\hline Dekker et al. (2011) & 1983-2008 (26) & $\$ 2.4$ million-\$7.5 million $^{\mathrm{d}}(2004)$ & $\$ 2.7$ million- $\$ 8.5$ million \\
\hline Lindhjem et al. $(2010)^{\mathrm{e}}$ & $1982-2007(26)^{\mathrm{e}}$ & $\$ 2.9$ million (2005) & $\$ 3.2$ million \\
\hline
\end{tabular}

${ }^{\text {a }}$ Stated-preference studies only. Kochi et al. (2006) also consider revealed-preference studies.

${ }^{\mathrm{b}}$ The Dekker et al. (2011) and Lindhjem et al. (2010) estimates are taken from the discussion of values for benefit transfer.

cAdjusted for inflation using the Consumer Price Index, All Urban Consumers. Not adjusted for income growth over time.

${ }^{\mathrm{d}}$ Range reflects mean estimates for road safety (\$2.4 million), air pollution (\$4.4 million), and general health (\$7.5 million) scenarios (2004 USD).

${ }^{e}$ Based on personal communication with H. Lindhjem, March 2011. Dates reflect when the data were collected rather than when the study was published; count reflects the number of surveys used to develop the estimate in the next column rather than the number of studies. The highlighted estimate is the median for OECD countries.

$\mathrm{CV}$ studies. They estimate the mean value of the hedonic wage distribution as $\$ 9.6$ million, which is significantly larger than the $\$ 2.8$ million mean for the CV studies (2000 USD).

Lindhjem et al. (2010), as well as a European study by Kluve \& Schaffner (2008), ${ }^{29}$ find that studies focused on traffic and environmental risks tend to yield higher VSLs than do studies focused on other health risks. In contrast, Dekker et al. (2011) find similar results for air pollution and unspecified causes and lower values for road safety. Although these diverse findings stem in part from differences in the underlying studies as well as from differences in statistical approach, they also suggest substantial VSL heterogeneity.

These meta-analyses, as well as the hedonic wage meta-analyses discussed above, differ in the universe of studies they consider and in the criteria they apply to select studies and estimates for their analyses. Kochi et al. (2006) and the older hedonic wage meta-analyses build on criteria originally developed by Viscusi (1992); some of the newer studies apply more restrictive criteria. Lindhjem et al. (2010) include the largest number of estimates and test the effects of different exclusion criteria as well as of different model specifications.

4.3.2. The impact of age and cause of death on VSL. Age and cause of death are two important features of mortality risk whose effect on VSL can, in principle, be studied using stated-preference methods. Such studies can measure the effect of respondent characteristics on WTP, assuming there is sufficient variation in these characteristics in the sample. To measure the effect of age independently of income or wealth, these variables must be measured in the survey and included in the final model. A good study allows age to enter the WTP function in a flexible form and demonstrates that results are robust to alternative specifications of the error term.

4.3.2.1. Age. On the basis of his review of 26 studies, Krupnick (2007) concludes that stated-preference studies provide little evidence of a substantial decline in VSL with age; however, few studies provide clear tests of the effect of age on VSL. Ideally, the effect of age

\footnotetext{
${ }^{29}$ Kluve \& Schaffner (2008) are excluded from Table 2 because they include only European studies.
} 
would be tested by using a series of dummy variables or other flexible specification rather than by imposing a linear or quadratic form on age. Few studies report results using a flexible functional form. Moreover, to measure the effect of age per se, studies should control for variables that may affect WTP and are likely to be correlated with age, such as income and wealth. No studies of which we are aware control for respondent wealth because these data are difficult to collect.

Stated-preference studies that address risks to children suggest that reductions in these risks may be valued more highly than reductions for adults (e.g., Hammitt \& Haninger 2010). However, Blomquist et al. (2011), in a stated-preference study that considers drugs that control asthma symptoms but also increase fatality risks, find that the relationship of VSL to age is complex, declining from ages 4 to 30 , increasing from ages 30 to 66 , and declining for older ages.

4.3.2.2. Cause of death. An important issue in valuing environmental risks is whether a different VSL should be used when valuing risk of death from different causes (e.g., different diseases). In the European Union and the United Kingdom, impact assessments may use a larger VSL for cancer because of the dreaded nature of the disease (European Commission 2000, H.M. Treasury 2003). In stated-preference studies, the effect of cancer is studied by varying the cause of death across valuation questions, holding other aspects of the risk constant. Risk-risk trade-off studies, in which the respondent chooses between options offering different changes in risk of death from various causes, also provide relevant information. ${ }^{30}$ A salient issue in valuing the effect of cancer is the timing of the risk. If a latency period precedes the development of cancer, then any discounting may be confounded with the cause of death. The survey must also make clear whether the respondent should consider the morbidity that precedes death.

The empirical evidence on the effect of cancer on VSL is mixed. In a telephone survey in Taiwan, Hammitt \& Liu (2004) elicited WTP to reduce risk of a fatal cancer or a noncancerous disease presenting the same symptoms and prognosis. The authors found that respondents were willing to pay $30 \%$ more, on average, to reduce the risk of cancer than to reduce the risk of the noncancerous disease. Van Houtven et al. (2008) conducted a risk trade-off study in which respondents were asked to choose among residential locations presenting different risks of several types of latent cancer and motor vehicle fatality. They found that respondents valued the cancer risks more than the motor vehicle risk with a differential that decreased with latency of the cancer from a factor of 3 for a 5 -year latency to a factor of 1.5 for a 25 -year latency.

In contrast, neither Hammitt \& Haninger (2010) nor Adamowicz et al. (2009) find a cancer risk premium in recent stated-preference studies. Hammitt \& Haninger (2010) find similar values for mortality risks from cancers, other diseases, and auto accidents. Adamowicz et al. (2009) find that the value of reducing cancer risks is slightly smaller than that for microbial risks (although the differences are often statistically insignificant).

\footnotetext{
${ }^{30}$ In a typical risk-risk study, respondents are asked whether they would prefer to live in a city with a risk of death from cancer of $x$ and a risk of death in a traffic accident of $y$, or in an otherwise identical city with a risk of death from cancer of $w$ and a risk of death in a traffic accident of $v$. The rate of substitution between the two risks can be estimated by varying the risk levels across respondents or by adjusting the risks until a respondent is indifferent between the two cities.
} 


\section{CONCLUSIONS}

For many years, mortality risk reductions associated with environmental policies have been valued on the basis of research conducted more than 20 years ago, as reviewed in Viscusi $(1992,1993)$ and incorporated into current EPA guidance (U.S. EPA 2010a). These values are derived primarily from hedonic wage studies, which do not address the types of illnesses and subpopulations most likely to be affected by environmental exposures. In addition, the data and methods used in these studies have improved substantially in recent years, and a number of new stated-preference studies now provide estimates for different types of risks and affected populations. In past analyses (e.g., U.S. EPA 2011), analysts tested the sensitivity of the results to different VSL estimates and/or to adjustments in the VSL to better fit the policy scenario. Our review suggests that it is time to replace the older set of studies with newer results.

Substantial improvements have been made in the conduct of hedonic wage studies. Over the past 35 years, dozens of these studies have been conducted in the United States and other high-income countries; however, many of the older studies suffer from both data and econometric problems. Chief among these are reliance on older and less accurate sources of risk data, the sensitivity of the coefficient on risk to inclusion and omission of other variables, and the endogeneity of job risk. For the United States, the first problem has been effectively addressed by creation of the CFOI, which is a census rather than a sample and includes substantially improved confirmation of the data. The first hedonic wage study relying on these data was published in 2003.

Progress has also been made on the second and third issues. Newer studies often control for both occupation and industry, as well as for nonfatal job risk and worker's compensation. However, collinearity continues to be a challenge, motivating a continuing search for data sets in which this is less problematic. The emergence of studies that use panel rather than cross-sectional data is an important advance. Use of instrumental variables and data from natural experiments may also aid in addressing the endogeneity of occupational risk.

The newer hedonic wage literature has not yet been synthesized in a meta-analysis. The meta-analyses available generally include studies that date back to the early 1970s; they do not analyze the more recent and methodologically superior studies. At minimum, such studies should use CFOI risk data and control for industry and occupation as well as nonfatal risks.

Although hedonic wage studies are limited in the types of risk and populations included, they provide insight into the magnitude of VSL and its variation with age. Some recent studies suggest an inverted-U relationship between VSL and age for working-age adults, whereas others suggest that this relationship may be more complex. In addition, some newer studies attempt to distinguish different types of job-related risks, suggesting heterogeneous values. However, irresolvable differences remain between the populations and risks addressed by hedonic wage studies and those affected by environmental programs. The importance of these differences, as well as possible adjustments, cannot be determined without turning to the stated-preference literature.

The stated-preference literature now includes many studies that address deaths associated with environmental hazards (cancers, heart disease, and respiratory disease), supplementing earlier studies that often focused on traffic safety. An increasing number of studies address populations older and younger (and potentially in poorer health) 
than the working-age individuals included in hedonic wage studies. Although respondents' difficulty in comprehending small risks continues to pose challenges, researchers have developed a better understanding of how to present risk concepts and to elicit WTP. In addition, increased emphasis on validity tests is improving interpretation of the results.

The growing number of stated-preference studies has allowed the increased use of metaanalysis. However, meta-analyses of stated-preference studies to date vary in the extent to which they exclude methodologically deficient studies. These meta-analyses also lead to conflicting findings on how the values of environmental risk reductions compare with the values of risk reductions from other causes. The set of studies that satisfy reasonable criteria for relevance and quality remains small. At minimum, stated-preference studies should demonstrate that WTP is sensitive to the size of the risk change as an indicator that respondents understand what they are being asked to value.

Although focusing on newer studies that meet these types of basic criteria for quality will improve the values used in environmental policy analysis, a number of issues need further investigation. Overall, VSL estimates from stated-preference studies appear consistently smaller than those estimated from hedonic wage studies. To some extent, these differences may result from the populations and types of risks each addresses. However, these differences may also reflect the strengths and weaknesses of each methodology and require more exploration.

Despite many recent studies of the effects of age on VSL, significant uncertainty remains, particularly for the very old and the very young. Given that older populations are often disproportionately affected by mortality risks from environmental causes and that children are often of significant concern for policy making, greater focus on the values appropriate for these age groups is needed.

An increasing number of stated-preference studies focus on fatal illness such as cancers, heart disease, and respiratory conditions. Yet the variation of VSL by cause of death remains unclear. More attention should be directed to how these illnesses are defined and compared, as well as to addressing other challenges faced in stated-preference research.

Finally, structural models that combine information about risk, income, leisure, savings, and other behavior can provide a unified framework for characterizing preferences and may yield more consistent estimates of how VSL varies among individuals. However, more work is needed to refine these models and to determine the most useful data sources (Smith et al. 2002, 2006; U.S. EPA 2010b).

Research on VSL has come a long way in recent years. Revealed-preference research has exploited new data sets and new statistical methods, and stated-preference research has expanded its coverage to different populations and types of risks. However, these types of research remain challenging. Given the importance of the value of mortality risk reductions to understanding the benefits of environmental policies, further research is warranted.

\section{DISCLOSURE STATEMENT}

The authors are not aware of any affiliations, memberships, funding, or financial holdings that might be perceived as affecting the objectivity of this review. 


\section{ACKNOWLEDGMENTS}

James K. Hammitt thanks the Institut National de Recherche Agronomique and the European Research Council (FP7/2007-2013 grant agreement 230,589) for financial support. We also thank V. Kerry Smith for his helpful comments on an earlier draft of this article.

\section{LITERATURE CITED}

Adamowicz W, Dupont D, Krupnick A, Zhang J. 2009. Valuation of cancer and microbial disease risk reductions in municipal drinking water: an analysis of risk context using multiple valuation methods. Unpubl. manuscr.

Alberini A. 1995. Optimal designs for discrete choice contingent valuation surveys: single-bound, double-bound and bivariate models. J. Environ. Econ. Manag. 28:287-306

Alberini A. 2005. What is a life worth? Robustness of VSL values from contingent valuation surveys. Risk Anal. 25(4):783-800

Alberini A, Cropper M, Krupnick A, Simon N. 2004. Does the value of a statistical life vary with age and health status? Evidence from the US and Canada. J. Environ. Econ. Manag. 48:769-92

Alberini A, Tonin S, Turvani M, Chiabai A. 2007. Paying for permanence: public preferences for contaminated site cleanup. J. Risk Uncertain. 34:155-78

Aldy JE, Viscusi WK. 2007. Age differences in the value of statistical life: revealed preference evidence. Rev. Environ. Econ. Policy 1(2):241-60

Aldy JE, Viscusi WK. 2008. Adjusting the value of a statistical life for age and cohort effects. Rev. Econ. Stat. 90(3):573-81

Arabsheibani GR, Marin A. 2000. Stability of estimates of the compensation for danger. J. Risk Uncertain. 20(3):247-69

Arabsheibani GR, Marin A. 2001. Union membership and the union wage gap in the UK. Labour $15(2): 221-36$

Bellavance F, Dionne G, Lebeau M. 2009. The value of a statistical life: a meta-analysis with a mixed effects regression model. J. Health Econ. 28:444-64

Biddle JE, Zarkin GA. 1988. Worker preference and market compensation for job risk. Rev. Econ. Stat. 70(4):660-67

Black DA, Galdo J, Liu L. 2003. How robust are hedonic wage estimates of the price of risk? Prepared for the U.S. Environ. Prot. Agency (U.S. EPA)

Black DA, Kniesner TJ. 2003. On the measurement of job risk in hedonic wage models. J. Risk Uncertain. 27(3):205-20

Blomquist G. 2004. Self-protection and averting behavior, values of statistical lives, and benefit cost analysis of environmental policy. Rev. Econ. Househ. 2:89-110

Blomquist GC, Dickie M, O’Conor RM. 2011. Willingness to pay for improving fatality risks and asthma symptoms: values for children and adults of all ages. Resour. Energy Econ. 33:410-25

Bowland BJ, Beghin JC. 2001. Robust estimates of value of a statistical life for developing economies. J. Policy Model. 23(4):385-96

Brown C. 1980. Equalizing differences in the labor market. Q. J. Econ. 94(1):113-34

Cameron TA. 2010. Euthanizing the value of a statistical life. Rev. Environ. Econ. Policy 4(2):161-78

Cameron TA, DeShazo JR. 2008. Demand for health risk reductions. Unpubl. manuscr.

Cameron TA, DeShazo JR, Stiffler P. 2010. Demand for health risk reductions: a cross-national comparison between the U.S. and Canada. J. Risk Uncertain. 41:245-73

Cameron TA, James MD. 1987. Efficient estimation methods for closed-ended contingent valuation surveys. Rev. Econ. Stat. 69(2):269-76

Corso PS, Hammitt JK, Graham JD. 2001. Valuing mortality-risk reduction: using visual aids to improve the validity of contingent valuation. J. Risk Uncertain. 23(2):165-84 
de Blaeij A, Raymond JG, Florax M, Rietveld P, Verhoef E. 2003. The value of statistical life in road safety: a meta-analysis. Accid. Anal. Prev. 35(6):973-86

Dekker T, Brouwer R, Hofkes M, Moeltner K. 2011. The effect of risk context on the value of a statistical life: a Bayesian meta-model. Environ. Resour. Econ. doi: 10.1007/s10640-011-9456-z

Deliere T, Khan S, Timmins C. 2009. Roy model sorting and non-random selection in the valuation of a statistical life. Unpubl. manuscr.

Dickie M, Fisher A, Gerking S. 1987. Market transactions and hypothetical demand data: a comparative study. J. Am. Stat. Assoc. 82(397):69-75

Dillingham A. 1985. The influence of risk variable definition on value of life estimates. Econ. Inq. 23(2):277-94

Dorman P, Hagstrom P. 1998. Wage compensation for dangerous work revisited. Ind. Labor Relat. Rev. 52(1):116-35

Eeckhoudt LR, Hammitt JK. 2001. Background risks and the value of statistical life. J. Risk Uncertain. 23(3):261-79

Eur. Comm. 2000. Recommended interim values for the value of preventing a fatality in DG environment cost benefit analysis. Rep. http://ec.europa.eu/environment/enveco/others/pdf/recommen ded_interim_values.pdf

Evans MF, Smith VK. 2006. Do we really understand the age-VSL relationship? Resour. Energy Econ. 28:242-61

Evans MF, Smith VK. 2008. Complementarity and the measurement of individual risk tradeoffs: accounting for quantity and quality of life effects. Environ. Resour. Econ. 41(3):381-400

Gegax D, Gerking S, Schulze W. 1991. Perceived risk and the marginal value of safety. Rev. Econ. Stat. 73(4):589-96

Gerking S, Haan M, Schulze W. 1988. The marginal value of job safety: a contingent valuation study. J. Risk Uncertain. 1:185-200

Hakes JJ, Viscusi WK. 2007. Automobile seatbelt usage and the value of statistical life. South. Econ. J. 73(3):659-76

Hammitt JK. 2000. Valuing mortality risk: theory and practice. Environ. Sci. Technol. 34:1396-400

Hammitt JK, Graham JD. 1999. Willingness to pay for health protection: inadequate sensitivity to probability? J. Risk Uncertain. 18(1):33-62

Hammitt JK, Haninger K. 2010. Valuing fatal risks to children and adults: effects of disease, latency, and risk aversion. J. Risk Uncertain. 40:57-83

Hammitt JK, Liu J-T. 2004. Effects of disease type and latency on the value of mortality risk. J. Risk Uncertain. 28(1):73-95

Hammitt JK, Robinson LA. 2011. The income elasticity of the value per statistical life: transferring estimates between high and low income populations. J. Benefit Cost Anal. 2(1):Artic. 1

Hammitt JK, Treich N. 2007. Statistical vs. identified lives in benefit-cost analysis. J. Risk Uncertain. 35:45-66

Hintermann B, Alberini A, Markandya A. 2010. Estimating the value of safety with labour market data: Are the results trustworthy? Appl. Econ. 42(7-9):1085-100

HM Treas. 2003. The Green Book: Appraisal and Evaluation in Central Government. London: TSO

Hwang H-S, Reed WR, Hubbard C. 1992. Compensating wage differentials and unobserved productivity. J. Polit. Econ. 100(4):835-58

Johannesson M, Johansson P-O, Lofgren K-G. 1997. On the value of changes in life expectancy: blips versus parametric changes. J. Risk Uncertain. 15:221-39

Kaplow L. 2005. The value of a statistical life and the coefficient of relative risk aversion. J. Risk Uncertain. 31(1):23-34

Kluve J, Schaffner S. 2008. The value of life in Europe-a meta-analysis. Sozial. Fortschr. $10-11: 279-87$

Kniesner TJ, Viscusi WK, Woock C, Ziliak JP. 2011. The value of statistical life: evidence from panel data. Work. Pap. No. 11-02, Law Econ., Vanderbilt Univ. Law Sch. 
Kniesner TJ, Viscusi WK, Ziliak JP. 2010. Policy relevant heterogeneity in the value of statistical life: new evidence from panel data quantile regressions. J. Risk Uncertain. 40(1):15-31

Kochi I, Hubbell B, Kramer R. 2006. An empirical Bayes approach to combining and comparing estimates of the value of a statistical life for environmental policy analysis. Environ. Resour. Econ. 34:385-406

Krueger AB, Summers LH. 1988. Efficiency wages and the inter-industry wage structure. Econometrica 56(2):259-93

Krupnick A. 2007. Mortality-risk valuation and age: stated preference evidence. Rev. Environ. Econ. Policy 1(2):261-82

Krupnick A, Cropper M, Alberini A, Simon N, O'Brien B, Goeree R. 2002. Age, health and the willingness to pay for mortality risk reductions: a contingent valuation survey of Ontario residents. J. Risk Uncertain. 24(2):161-75

Lanoie P, Pedro C, Latour R. 1995. The value of a statistical life: a comparison of two approaches. J. Risk Uncertain. 10:235-57

Leigh J. 1995. Compensating wages, value of a statistical life, and inter-industry differentials. J. Environ. Econ. Manag. 28(1):83-97

Lindhjem H, Navrud S, Braathen NA. 2010. Valuing lives saved from environmental, transport, and health policies: a meta-analysis of stated preference studies. Rep., ENV/EPOC/WPNEP(2008)10/ FINAL, Organ. Econ. Coop. Dev.

Liu J-T, Hammitt JK. 1999. Perceived risk and the value of workplace safety in a developing country. J. Risk Res. 2(3):263-75

Liu J-T, Hammitt JK, Liu J-L. 1997. Estimated hedonic wage function and value of life in a developing country. Econ. Lett. 57(3):353-58

Lott JR Jr, Manning RL. 2000. Have changing liability rules compensated workers twice for occupational hazards? J. Legal Stud. 29(1):99-130

Miller TR. 2000. Variations between countries in values of statistical life. J. Transp. Econ. Saf. 34(2):169-88

Mitchell RC, Carson RT. 1989. Using Surveys to Value Public Goods: The Contingent Valuation Method. Washington, DC: Resour. Future

Mrozek JR, Taylor LO. 2002. What determines the value of life? A meta-analysis. J. Policy Anal. Manag. 21(2):253-70

Natl. Ocean. Atmos. Admin. (NOAA). 1993. Natural resource damage assessments under the Oil Pollution Act of 1990. Fed. Regist. 58(10):4601-14

Robinson LA. 2007. How U.S. government agencies value mortality risk reductions. Rev. Environ. Econ. Policy 1(2):283-99

Robinson LA, Hammitt JK. 2011. Valuing health and longevity in regulatory analysis: current issues and challenges. In Handbook on the Politics of Regulation, ed. D Levi-Faur, Chpt. 30. Cheltenham, UK/Northampton, MA: Edward Elgar. In press

Scotton CR, Taylor LO. 2011. Valuing risk reductions: incorporating risk heterogeneity into a revealed preference framework. Resour. Energy Econ. 33(2):381-97

Shogren JF, Stamland T. 2002. Skill and the Value of Life. J. Polit. Econ. 110(5):1168-73

Smith VK, Evans MF, Kim H, Taylor DH Jr. 2004. Do the near-elderly value mortality risks differently? Rev. Econ. Stat. 86(1):423-29

Smith VK, Pattanayak SK, Van Houtven GL. 2006. Structural benefit transfer: an example using VSL estimates. Ecol. Econ. 60:361-71

Smith VK, Van Houtven GL, Pattanayak SK. 2002. Benefit transfer via preference calibration: prudential algebra for policy. Land Econ. 78(1):132-52

Thaler R, Rosen S. 1976. The value of saving a life: evidence from the labor market. In Household Production and Consumption, ed. N Terleckyz, pp. 265-302. New York: Columbia Univ. Press

Turnbull BW. 1974. Nonparametric estimation of a survivorship function with doubly censored data. J. Am. Stat. Assoc. 69:169-73 
U.S. Environ. Prot. Agency (U.S. EPA). 2010a. Guidelines for preparing economic analysis. EPA 240-R-10-001. http://yosemite.epa.gov/ee/epa/eed.nsf/pages/Guidelines.html

U.S. EPA. 2010b. Valuing mortality risk reductions for environmental policy: a white paper. Prepared for consultation with the Science Advisory Board-Environmental Economics Advisory Committee

U.S. EPA. 2011. The benefits and costs of the Clean Air Act from 1990 to 2020. Rep., U.S. EPA, Washington, DC. http://www.epa.gov/oar/sect812/prospective2.html

U.S. Office of Management and Budget (U.S. OMB). 2010. 2010 report to Congress on the benefits and costs of federal regulations and unfunded mandates on state, local, and tribal entities. Rep., U.S. OMB, Washington, DC. http://www.whitehouse.gov/omb/inforeg_regpol_reports_ congress/

Van Houtven G, Sullivan MB, Dockins C. 2008. Cancer premiums and latency effects: a risk tradeoff approach for valuing reductions in fatal cancer risks. J. Risk Uncertain. 36:179-99

Viscusi WK. 1992. Fatal Trade-Offs: Public and Private Responsibilities for Risk. New York: Oxford Univ. Press

Viscusi WK. 1993. The value of risks to life and health. J. Econ. Lit. 31:1912-46

Viscusi WK. 2003. Racial differences in labor market values of a statistical life. J. Risk Uncertain. 27(3):239-56

Viscusi WK. 2004. The value of life: estimates with risks by occupation and industry. Econ. Inq. 42(1):29-48

Viscusi WK. 2009. The devaluation of life. Regul. Gov. 3:103-27

Viscusi WK, Aldy JE. 2003. The value of a statistical life: a critical review of market estimates throughout the world. J. Risk Uncertain. 27(1):5-76

Viscusi WK, Hersch J. 2001. Cigarette smokers as job risk takers. Rev. Econ. Stat. 83(2):269-80

Viscusi WK, Moore MJ. 1991. Worker learning and compensating differentials. Ind. Labor Relat. Rev. 45(1):80-96 
Annual Review of

Resource Economics

Volume 3, 2011

\section{Contents}

\author{
Prefatory
}

Plowing Through the Data

Yair Mundlak.............................. 1

Methods for Performance Evaluations and Impact Measurement

Green National Income and Green National Product John M. Hartwick . . . . . . . . . . . . . . . . . . . . 21

Behavior, Robustness, and Sufficient Statistics in Welfare Measurement

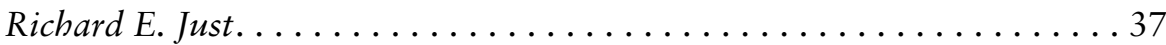

The Challenges of Improving the Economic Analysis of Pending Regulations: The Experience of OMB Circular A-4 Art Fraas and Randall Lutter . . . . . . . . . . . . . . . . . . 71

The Economics of Commodity Markets and Food Supply Chains

Commodity Booms and Busts Colin A. Carter, Gordon C. Rausser, and Aaron Smith. . . . . . . . . . . . 87

Food Quality: The Design of Incentive Contracts Rachael E. Goodhue ... . . . . . . . . . . . . . . . . . . . . . . 119

Nutritional Labeling and Consumer Choices Kristin Kiesel, Jill J. McCluskey, and Sofia B. Villas-Boas.

The Economics and Policy of Natural Resources

Efficiency Advantages of Grandfathering in Rights-Based Fisheries Management Terry Anderson, Ragnar Arnason, and Gary D. Libecap . . . . . . . . . . 159

Game Theory and Fisheries Rögnvaldur Hannesson . . . . . . . . . . . . . . . . . . . 181 
Natural Resource Management: Challenges and Policy Options

Jessica Coria and Thomas Sterner . . . . . . . . . . . . . . . . . . . . . 203

The New Economics of Evaluating Water Projects

Per-Olov Johansson and Bengt Kriström . . . . . . . . . . . . . . 231

The Economics of Human and Environmental Health Risks

Management of Hazardous Waste and Contaminated Land Hilary Sigman and Sarah Stafford . . . . . . . . . . . . . . . 255

The Economics of Infection Control

Mark Gersovitz . . . . . . . . . . . . . . . . . . . . . . . . . . . . . . . . 277

The Economics of Natural Disasters

Derek Kellenberg and A. Mushfiq Mobarak. . . . . . . . . . . . . . . . . . 297

Valuing Mortality Risk Reductions: Progress and Challenges

Maureen Cropper, James K. Hammitt, and Lisa A. Robinson. . . . . . . . 313

Environmental Economics and Policy

Pricing Nature

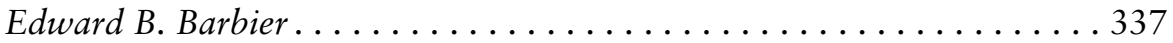

The Economics of Non-Point-Source Pollution

Anastasios Xepapadeas ........................... 355

Microeconometric Strategies for Dealing with Unobservables and

Endogenous Variables in Recreation Demand Models

Klaus Moeltner and Roger von Haefen. . . . . . . . . . . . . . . . . 375

The Environment and Trade

Larry Karp . . . . . . . . . . . . . . . . . . . . . . . . . . . . . . . 397

The Social Cost of Carbon

Richard S.J. Tol ............................ 419

Corporate Average Fuel Economy Standards and the Market for

New Vehicles

Thomas Klier and Joshua Linn.

\section{Errata}

An online log of corrections to Annual Review of Resource Economics articles may be found at http://resource.annualreviews.org 